\title{
Data Monitoring Committee Indicator
}

National Cancer Institute

\section{Source}

National Cancer Institute. Data Monitoring Committee Indicator. NCI Thesaurus. Code C127790.

An indication as to whether a clinical trial has an appointed data monitoring committee. 